\title{
Influence of back extensor strength on the natural history of kyphosis
}

\author{
Michio Hongo ${ }^{*}$, Naoshisa Miyakoshi, Yuji Kasukawa, Yoshinori Ishikawa, Daisuke Kudo, Yoichi Shimada \\ From The 10th Meeting of the International Research Society of Spinal Deformities (IRSSD 2014 Sapporo) \\ Sapporo, Japan. 29 June - 2 July 2014
}

\section{Introduction}

Previous cross-sectional study demonstrated that spinal kyphosis was signiflcantly associated with back extensor strength. However, the influence of trunk muscle on the development of kyphosis is still unclear due to the paucity of longitudinal study. The purpose of this study was to evaluate the association of back extensor strength and progression of kyphosis with longitudinal follow up.

\section{Methods}

Thirty women with an average age of 66 years were included in the study. They were followed up for more than two years. Participants who had severe kyphosis with 2 or more vertebral fractures or recent fracture within 6 months and who had underwent back strengthening exercise were excluded. Thoracic kyphosis, thoraco-lumbar, lumbar lordosis, pelvic tilt, sacral slope, pelvic incidence, and sagittal vertical axis were measured with lateral standing radiographs of whole spine including pelvis at the baseline and final follow-up. Isometric back extensor strength and grip strength were also measured with dynamometer.

\section{Results}

Significant changes were found in sagittal vertical axis $(13.9 \mathrm{~mm}$ to $24.8 \mathrm{~mm}, \mathrm{p}=0.008)$ and thoracolumbar kyphosis (7.5 degrees to 9.8 degrees, $\mathrm{p}=0.02$ ). Whereas, there was no significant change in the measurements for thoracic kyphosis, lumbar lordosis, pelvic tilt, pelvic incidence, sacral slope, back extensor strength, and grip strength at the final follow up. Then analyses were performed to evaluate the factors contributing to the increase in sagittal vertical axis. The change in sagittal vertical axis was significantly correlated with age, grip

Department of Orthopedic Surgery, Akita University Graduate School of Medicine, Japan strength, and back extensor strength, but not with other radiographic spino-pelvic measurements.

\section{Conclusion}

Increase in sagittal vertical axis was significantly associated with back extensor strength and grip strength, irrespective of spin-pelvic alignment, indicating the importance of strengthening the physical performance including back extensor strength for preventing the development of spinal kyphosis.

Published: 19 January 2015

doi:10.1186/1748-7161-10-S1-O27

Cite this article as: Hongo et al:: Influence of back extensor strength on the natural history of kyphosis. Scoliosis 2015 10(Suppl 1):O27.

\section{Submit your next manuscript to BioMed Central and take full advantage of: \\ - Convenient online submission \\ - Thorough peer review \\ - No space constraints or color figure charges \\ - Immediate publication on acceptance \\ - Inclusion in PubMed, CAS, Scopus and Google Scholar \\ - Research which is freely available for redistribution

